\title{
Underpinning of shallow foundations by expansive polyurethane resin injections. Case study: Cardinal Diego de Espinosa Palace in Segovia (Spain)
}

\section{Recalce de cimentaciones superficiales mediante la inyección de resina de poliuretano expandido. Caso de estudio: Palacio del Cardenal Diego Espinosa, en Segovia (España)}

\section{Félix Escolano Sánchez (Main Author)}

Escuela Técnica Superior de Ingeniería Civil, Universidad Politécnica de Madrid Alfonso XII, 3 y 5 - 28014 Madrid (Spain)

felix.escolano@upm.es

\section{Alberto Mazariegos de la Serna (Corresponding Author)}

Departamento de Ingeniería Civil: Construcción, Infraestructura y Transporte

Escuela Técnica Superior de Ingeniería Civil, Universidad Politécnica de Madrid Alfonso XII, 3 y 5 - 28014 Madrid (Spain)

alberto.mazariegos@upm.es

\section{José Ramón Sánchez Lavín}

Escuela Técnica Superior de Ingeniería Civil, Universidad Politécnica de Madrid Alfonso XII, 3 y 5 - 28014 Madrid (Spain)

joseramon.sanchez@upm.es

\section{José María del Campo Yagüe}

Escuela Técnica Superior de Ingeniería Civil (Universidad Politécnica de Madrid) Alfonso XII, 3 y 5 - 28014 Madrid (Spain) josemaria.delcampo@upm.es

Manuscript Code: 771

Date of Acceptance/Reception: 04.12.2017/11.05.2016

DOI: $10.7764 / R D L C .16 .3 .420$

\begin{abstract}
The injection of expansive polyurethane resin into the soil is a technology that is beginning to be used for underpinning shallow foundations. It is noteworthy that this technology has been used on buildings of great historical value which are part of the country's architectural heritage. This article describes the work done on the Cardinal Diego de Espinosa Palace which consisted of injecting expanding polyurethane resin into the soil at different depths (Uretek Deep Injections) in order to mitigate the differential settlements detected in the structure. This injection technology has proven to be more effective than the more convention methods used in the past which consisted of raising the foundation by building concrete shafts, which did not manage to mitigate the causes of the pathologies observed in the palace.
\end{abstract}

Key words: Underpinning, Injection, Expansive Resins, Historical buildings

Resumen

La inyección en el terreno de resina de poliuretano expansivo es una tecnología que se está comenzando a utilizar en el recalce de las cimentaciones superficiales. En este sentido, resulta más enriquecedor llamar la atención sobre aquellas actuaciones realizadas que, por ser edificaciones con un valor histórico relevante, forman parte del patrimonio arquitectónico de un país. El presente artículo describe la actuación realizada en el edificio histórico del Palacio del Cardenal Diego de Espinosa, consistente en la inyección de resina de poliuretano expansivo en el terreno a diferentes profundidades (Uretek Deep Injections), encaminada a mitigar la presencia de asientos diferenciales detectados en su estructura. Esta tecnología de inyección ha mostrado ser más efectiva que las anteriores actuaciones de recalce convencionales realizadas, recrecidos de la cimentación mediante la construcción de pozos de hormigón, en las que no se consiguieron mitigar las causas de las patologías observadas en el palacio.

Palabras clave: Recalce, Inyección, Resinas expansivas, Edificios históricos

Introduction

Because of Spain's rich architectural heritage, with increasing frequency architects and engineers are faced with situations in which historical buildings and other one of a kind structures are affected by settlements that can worsen 
over time. Occasionally, the problem can progress to the point where the conservation of these cultural assets may be jeopardised.

In most cases, and due to the age of these one-of-a-kind structures, the pathologies are due to the soil conditions of the foundations (Escolano-Sánchez, F., Bueno-Aguado, M., \& Fernández-Ordóñez, 2015). The soil supporting the foundation changes over time, mainly due to anthropic activities, and this places additional stress on the foundation causing deformations that are very different than the ones that prevailed during construction and for which the original foundation was not designed.

These pathologies are often causes by the presence of differential settlements, which can sometimes place the conservation of the building for future generations in jeopardy. There are three factors that contribute to these settlements:

a) Variations in the distribution of permanent loads, caused mainly by interventions to enlarge, renovate or otherwise modify the building structure.

b) Changes in the mechanical properties of the soil supporting the foundation, triggering a new distribution of tensions. The new tension field can be caused by:

- Leaks or cracks in water pipes affecting the foundation soil.

- Fluctuations in the water table in the area.

- Physical and chemical degradation of the foundation.

c) A combination of these.

However, in any of the factors listed above, the action to be taken should be designed so that the soil-structure interaction is able to adapt to new tension scenario (Escolano Sánchez, Bueno Aguado, \& Lavín, 2014). This adaptation can be achieved by underpinning the foundation using a technique that injects expanding polyurethane resin into the supporting soil in order to consolidate and enhance its mechanical properties, which is precisely the case that is described in this article.

\section{State of The Art}

In traditional injection techniques it is common to use a mixture of water and cement with additives, or nonexpanding resins. The design objectives of these treatments are controlled by the type and quantity of the components present in the mixture, the injection pressure and the volume allowed, which determines the area of influence of the consolidation. Injecting expanding polyurethane resins is different due to the chemical nature of its components, polyurethanes. In fact, they require no injection pressure. The solidified resin achieves a natural balance with the surrounding soil when the swelling pressure of the resin as a result of the reaction coincides with the average confining pressure of the soil.

In this article, we will show how the mechanical properties of the foundation soil can also be improved by injecting expanding polyurethane resin into the soil to make it stronger.

\section{Basic concepts of expanding polyurethane resin}

Expanding polyurethane resins are produced by the exothermic reaction between a polyol and an isocyanate when combined in volumetrically established proportions. During the chemical reaction, a large amount of carbon dioxide is produced which causes the volumetric expansion of the mixture and formation of a spongy structure where the gas bubbles are trapped. The production of carbon dioxide requires the presence of water which reacts with isocyanate group. In the absence of water, a chemically inert swelling agent with a low boiling point is used, which is vaporized consuming part of the polymerization heat.

The mixture changes from a liquid to a solid and hardens in a very short time. The reaction time, which depends on the particular resin and catalysts used, is influenced by the temperature of the admixed components. By controlling the temperature of the components it is therefore possible to speed up or slow down the reaction time. The pressure exerted during the swelling and the final position of the resin depends on the expansion capabilities of the gas in the bubbles before it hardens. The "closed cell" structure of the expanded resin is shown in Figure 1 . The images were obtained using an electron microscope (Buzzi, O., Fityus, S., Sasaki, Y., \& Sloan, 2008) 
Figure 1. Images obtained with the electron microscope of the Geoplus
expanding polyurethane resin without confinement (density equal to 37 $\mathrm{kg} / \mathrm{m}^{3}$ ). (A) Enlarged x 100; (B) Enlarged x 200. (Buzzi et al., 2008).

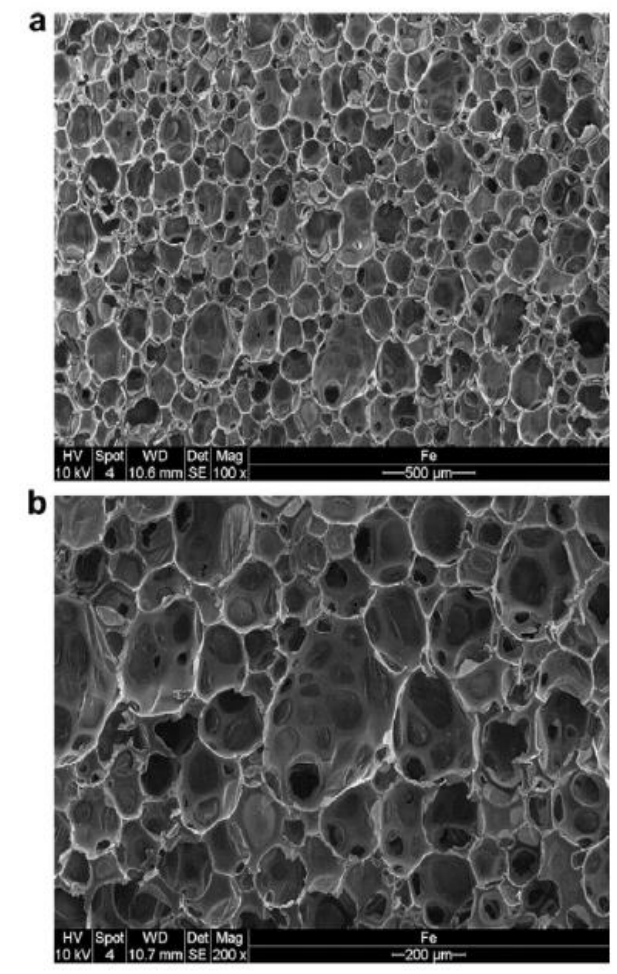

The images of Figure 1 shows the microscopic structure of the resin used by Uretek under free swell conditions corresponding to a density equal to $37 \mathrm{~kg} / \mathrm{m}^{3}$. The density of the liquid mixture is equal to $1070 \mathrm{~kg} / \mathrm{m}^{3}$, very close to that of water. Under these conditions, the expanding volume is equal to 30 times the original volume of the mixture. (Dei Svaldi, Favaretti, Pasquetto, \& Vinco, 2005)

The mechanical properties of the resins can be found in the studies conducted by accredited European laboratories (Manassero, Dominijanni, Foti, \& Musso, 2016)(Buzzi, Fityus, \& Sloan, 2010)

Of particular note is the fact that the mechanical resistance of the expanded and hardened resin depends on the degree of expansion. For specific gravities between 0.5 and $3.3 \mathrm{kN} /{ }^{3}$, the resistance values are between 0.2 and 6.0 $\mathrm{MPa}$.

The elastic modulus of the resin is comparable to that of any type of soil where a foundation is built. It can vary between 10 and $80 \mathrm{MPa}$ depending on the density obtained after polymerization of the resin (Table 1).

\begin{tabular}{lcc} 
& Table 1. Elastic modulus in different types of soil. Source: Author's property. \\
\hline Soil type & Elastic modulus & Elastic modulus of resin \\
& $E(\mathrm{MPa})$ & \\
\hline Sand & 10 to 25 & 10 to 80 \\
Medium sand compactness & 15 to 30 \\
Dense sand compactness & 35 to 55 & \\
Sand and gravel & 70 to 180 & \\
Medium consistency clay & 5 to 10 & \\
Hard clay & 10 to 25 & \\
\hline
\end{tabular}

Consistent with the above, it can be concluded that after injecting Geoplus expanding polyurethane resin the volume of treated soil does not modify the rigidity or distribution of force under the treated area. In other words, there is no creation of "hard points" in the soil and the procedure for injecting resin can be considered suitable for partial or localized treatment (Henderson, Taylor, Harris, Mair, \& Love, 1994) (Manassero, Dominijanni, Foti, \& Musso, 2013). 


\section{Injection technology}

Injection technology that uses Uretek Deep Injections allows you to inject Geoplus polyurethane resin into the soil at different depths through small perforations, causing minimal disturbance to structures and the overlying ground in order to solve problems related to the capacity of the ground under foundations.

The treated soil is consolidated in a vertical or sub-vertical direction thanks to a succession of low pressure injections of the resin under the foundation.

Once the resin injected into the soil expands, the soil interface can re-established at different depths and in areas where the admissible stress values are low (Figure 2). A better load distribution is thus achieved and the tension peaks under the foundation are limited.

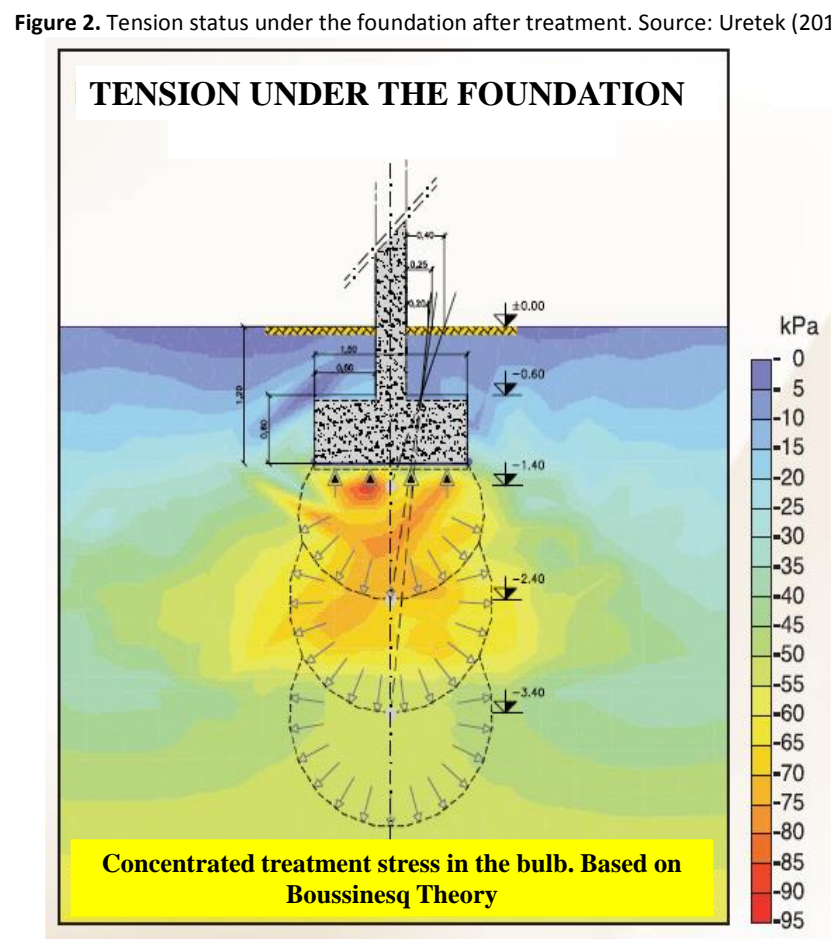

\section{Injection procedure}

The procedure used is based on drilling holes less than $30 \mathrm{~mm}$ (typically between 12 and $26 \mathrm{~mm}$ ), spaced between 50 and $150 \mathrm{~cm}$ apart. Figure 3 (a). Metal pipes are then inserted into these holes down to the established depths, Figure 3 (b), and the expanding resin is injected into the soil through the pipes.

Figure 3. Stages of the process: (a) Drilling, (b) Introduction of the injection pipes. Source: Author's property.

(a)

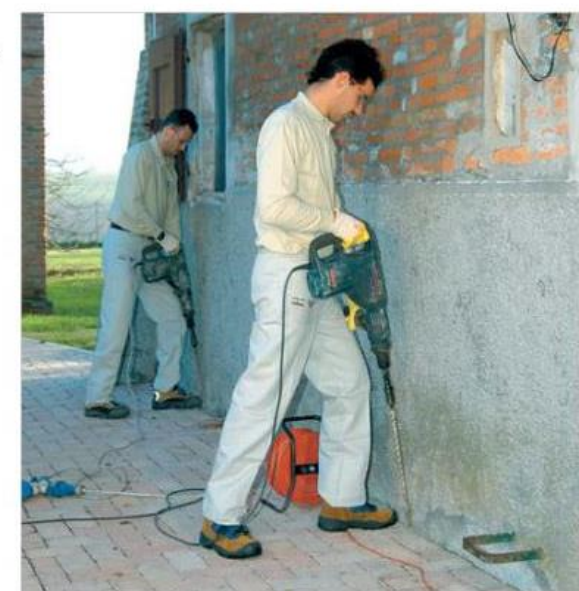

(b)

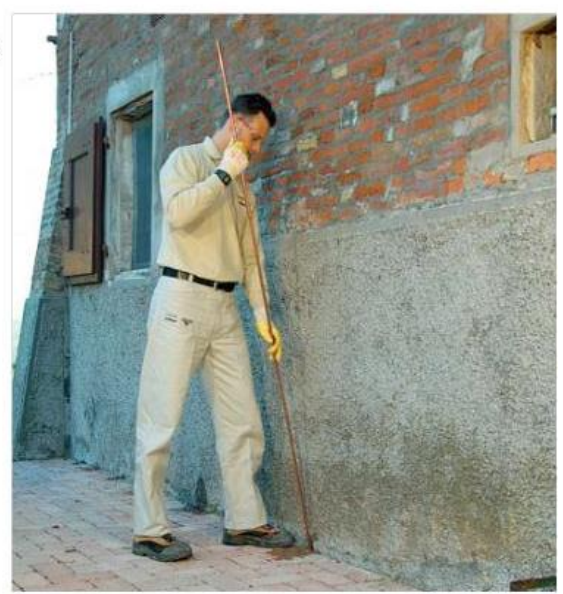


The injection is controlled following specific protocol. The two basic points of this injection protocol include the injection head of the resin, Figure 4 (a) and the laser level that controls the lifting of the structure, Figure (b).

Figure 4. Implementation phases: (a) resin injection head, (b) laser level to control lifting. Source: Author's property.
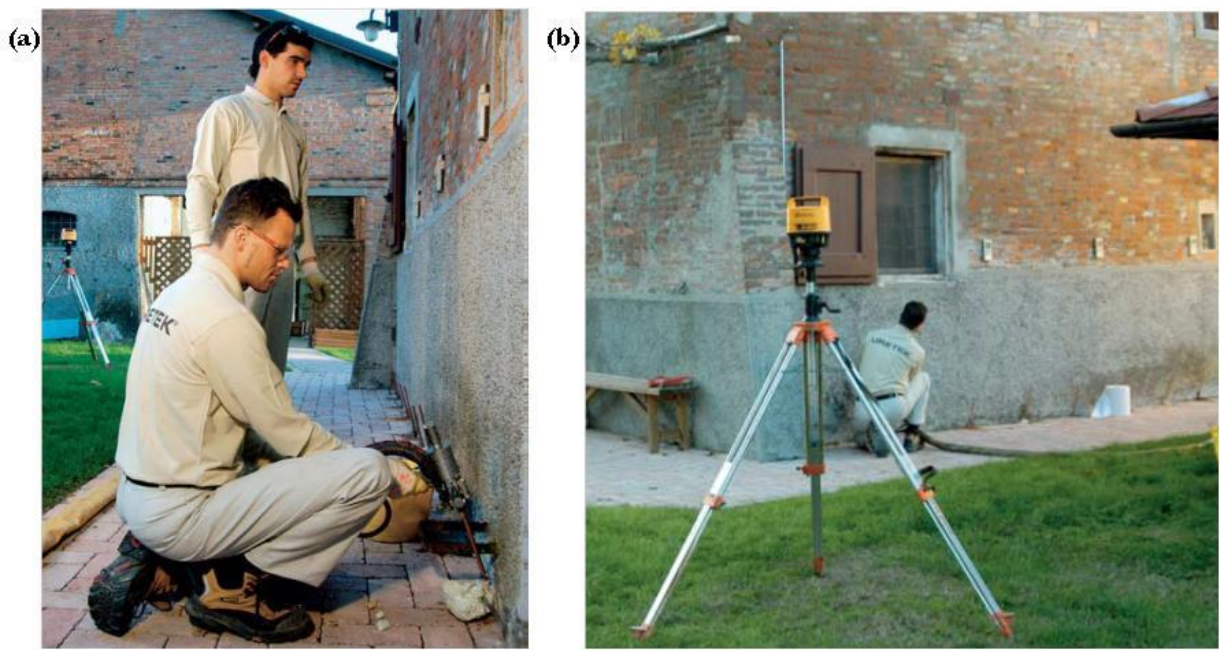

The resin is injected into the soil in a liquid state. Almost instantly, a chemical reaction is triggered causing an increase in volume and the resin changes from a liquid to solid state. The expansion pressure of the resin can reach $10,000 \mathrm{kPa}$. The reaction begins and ends very quickly. The resin reaches its final physical-chemical characteristics in a few seconds.

When the resin penetrates the soil to be treated and increases in volume, it compresses the soil in all directions. This radial expansion is favoured by the pathways that offer the least resistance. The resin continues to expand until the soil prevents any further radial compression. At that point, the only possibility for expansion is an upward displacement of the soil (Figure 5).

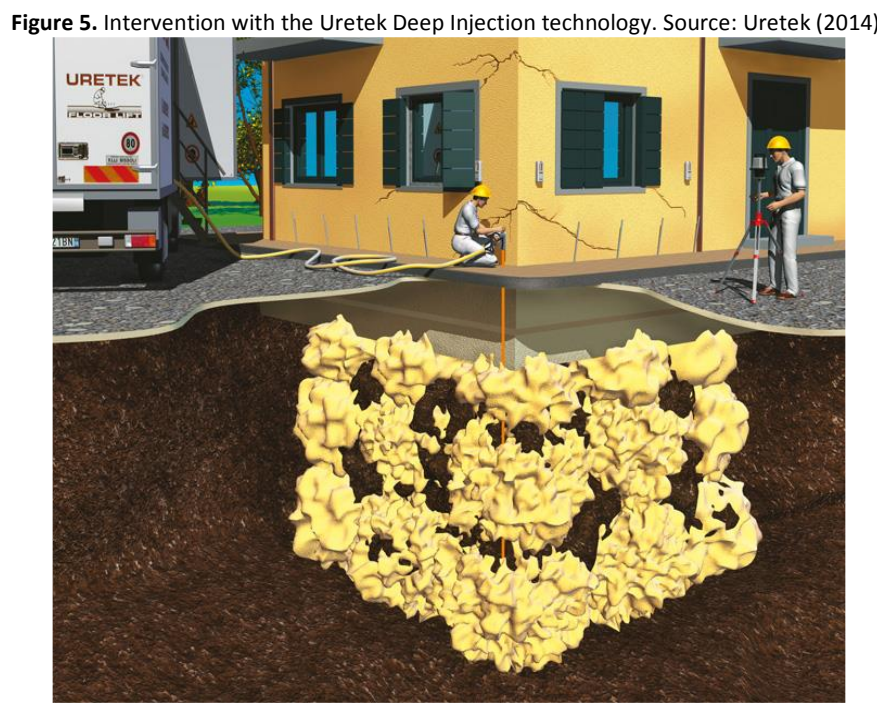

When this initial lifting is observed, it means that the consolidating action is being directed vertically upward and that this is the direction that offers the least resistance, while the surrounding soil offers greater resistance in respect of the decrease in the structural load, which means that the foundation soil has been compacted enough to withstand not only the increase in static loads, but also the loads created by the lifting (Bilotta, 2013) (Apuani et al., 2015)(Buzzi, O., Fityus, S., Sasaki, Y., \& Sloan, 2008)(VINSON \& Mitchell, 1972).

This initial raising of the structure (tenths of $\mathrm{mm}$ ), is what makes it possible to confirm the effectiveness of the method in real time. When the resin is injected at different depths, the injection usually begins with the top level, proceeding to the next level once the resin mixture hardens. 
During the injection, the amount of mixture used is measures at each injection point and compared with the nominal consumption for the project. After the injection, a laser level is used to detect any vertical movement of the treated structure. This is the most efficient way to check the effectiveness of soil treatment in real time.

Description of the Problem

\section{History of the cardinal Diego de Espinosa Palace}

The palace is a historic building dating back to the year 1570. It is believed to have been designed by Juan Bautista de Toledo, an architect who trained in Italy. He had experience in urban planning, military and hydraulic engineering and was the Royal Architect during the reign of Philip II. The structure is one of the most outstanding examples of Spanish Renaissance architecture, which in those days called for an austere, simple and monumental architectural style in tune with the ideals of the Counter-Reformation.

\section{Building features}

The building is located in the town of Martin Munoz de Posadas in Segovia. It is rectangular in shape with a square interior courtyard and several outbuildings. The facade is brick with a base of granite stone masonry (Figure 6). It has two floors above ground level. The lower level has a gallery with semi-circular arches and Tuscan columns. The upper level is seated on lonic columns with footings.
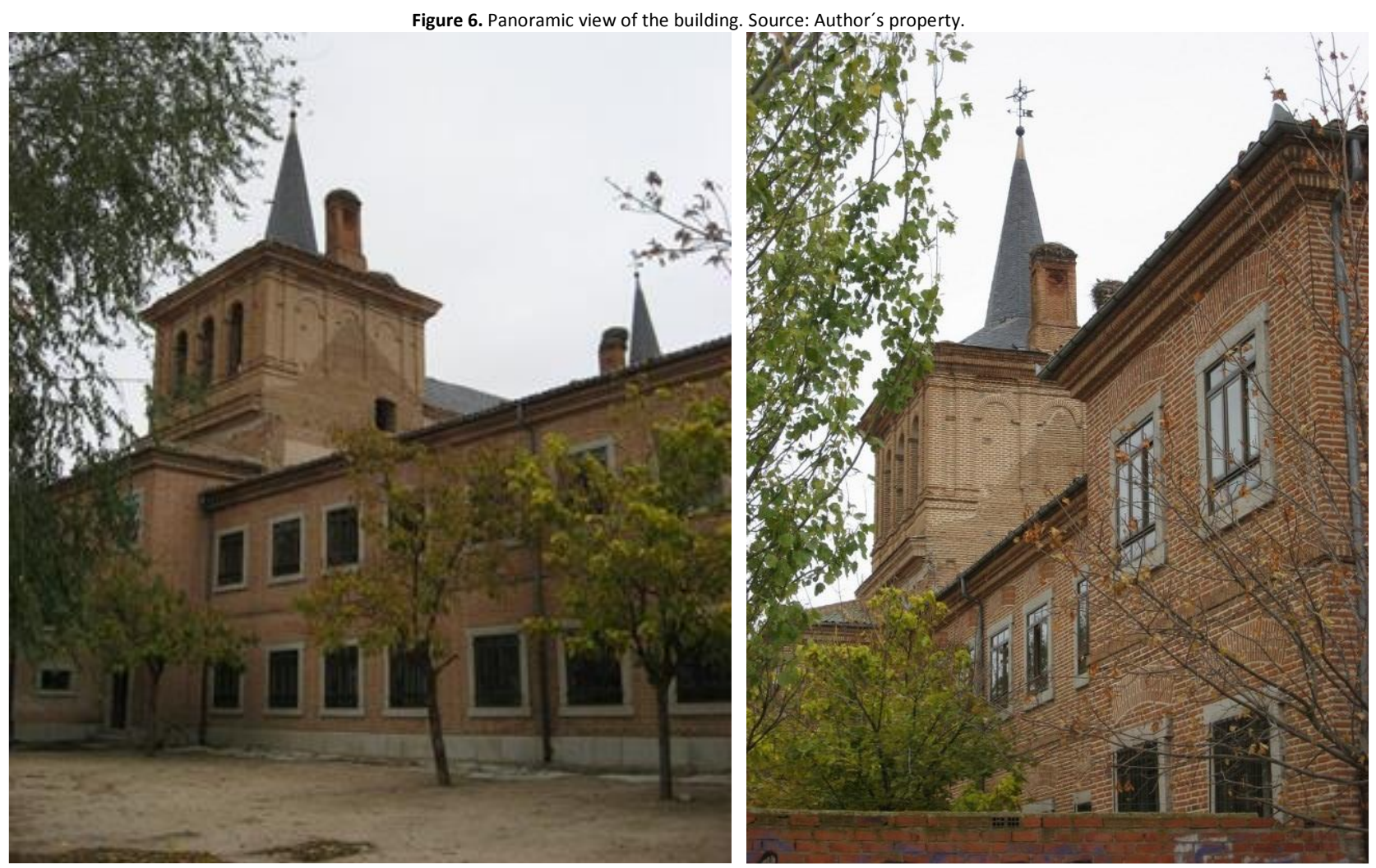

\section{Pathologies observed}

The presence of differential settlements in the building is not a new pathology. There was a previous effort to mitigate this pathology by lifting the foundation. In order to do so, concrete shafts measuring between 2.20 and 2.40 meters deep were built. However, new cracks of a considerable magnitude appeared reappeared a few years ago.

According to information available from the time of that action, the settlement was caused by changes in the mechanical properties of the clayey foundation soil which caused a shift in the distribution of the stress. This new stress scenario was presumably triggered by water leaks from the sewer system. In addition, the depth of the water table located near the building foundation fluctuates significantly throughout the year. 


\section{Design and dimensioning of the intervention}

According to the available geotechnical information, the building foundation rests on an orange clay substrate up to 4.00 meter thick.

When a clayey material such as this, with a prominently cohesive nature according to the Technical Building Code (Código Técnico de la Edificación, 2006), gets wet as a result of unnatural causes (leaks), this leads to a considerable impairment of its consistency and causes a shift in the stress.

This new scenario could be the cause of the pathology since this type of clay is unsuitable for supporting the weight of the building. This hypothesis is supported by the new $45^{\circ}$ cracks and fissures leading downward into the ground, with a stepped course that is typical of brick masonry.

Consequently, the treatment zones were defined on the basis of the damages observed and the soil features described here so that it was possible to limit the treatment to those parts of the foundation that had sustained differential settlement.

The action should be limited to the area of influence of the foundation (Boussinesq bulb) or to a certain "level", established on the basis of the available geotechnical information. Based on these conditioning factors, the treatment area was limited to an area of 50 linear meters under one of the load-bearing walls which make up the building foundation (Figure 7).

Figure 7. Ground and elevation plan of the treated area of the building. Source: Author's property.
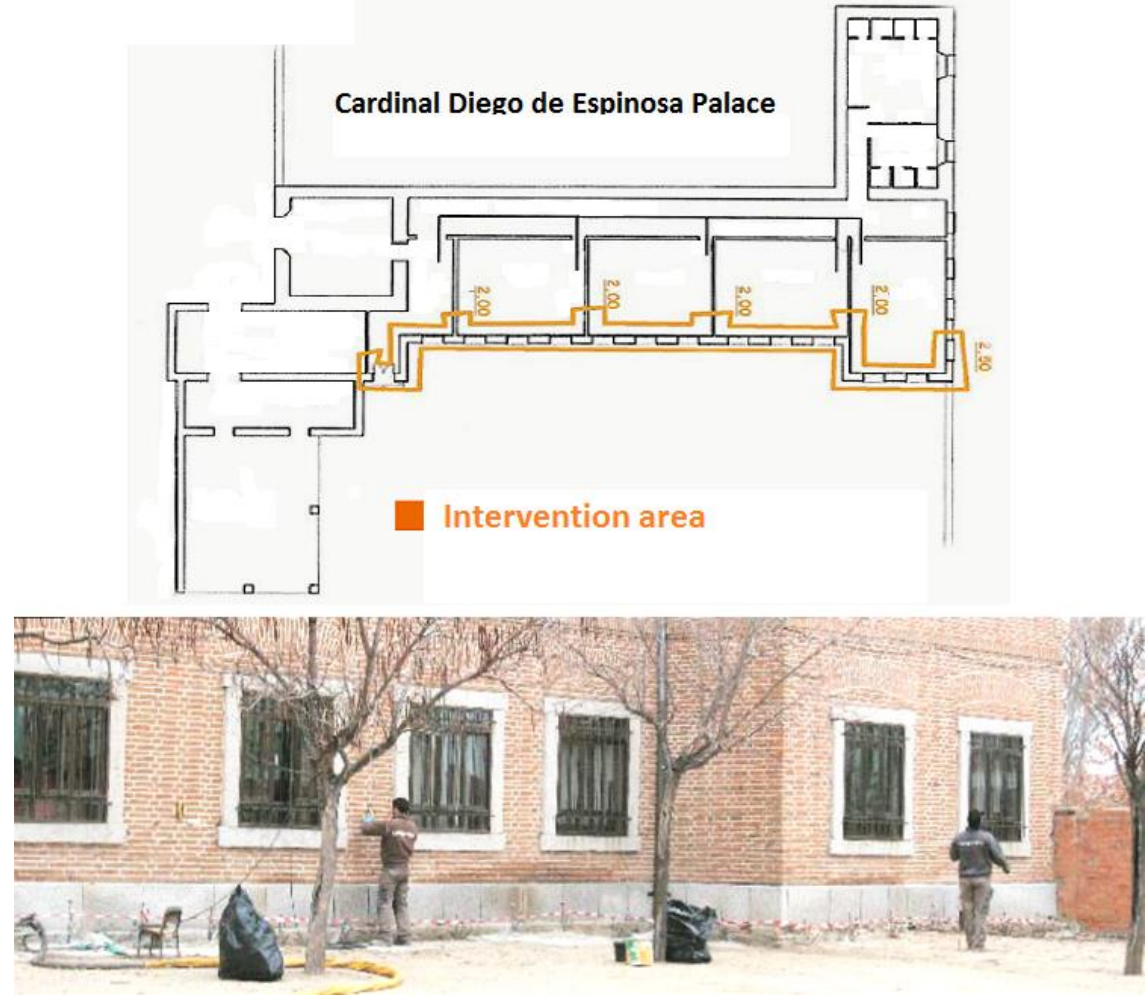

The intervention was divided into two phases:

- Phase I. Surface compaction. Injections at the foundation support foundation level in order to improve the geomechanical characteristics of the soil and fill in the gaps between the foundation and the soil.

- Phase II. Deep consolidation. Injections performed at different depths (3 levels) into the soil affected by the building loads. 
The number of vertical injection levels is based on the depth of the soil to be treated, starting from the reference level of the deformation bulb in the soil affected by the foundation. Injection levels are usually spaced between 0.5 to 1.0 m apart (Figure 8).

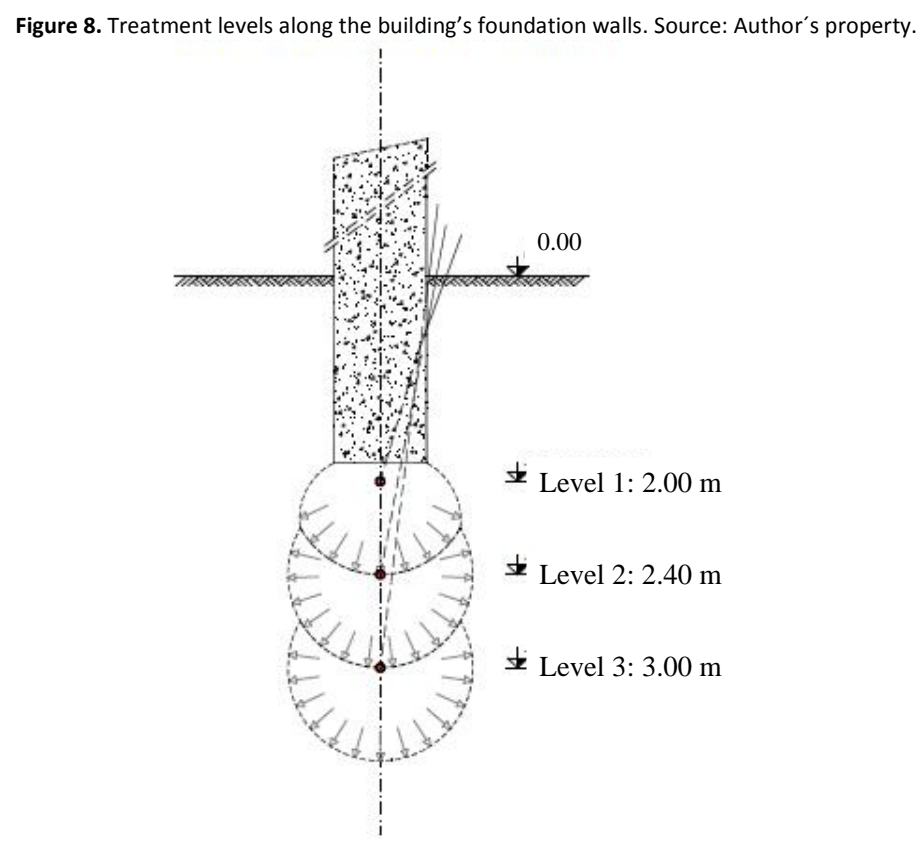

\section{Foundation underpinning using resin injection}

The underpinning of the foundation was performed by injecting Geoplus expanding polyurethane resin using Uretek technology (Uretek Deep Injections). The resin injection phases included in the protocol:

- Drilling and installation of injection pipes.

- Injection of the resin.

- Instrumentation and control of the injection.

\section{Drilling and installation of injection pipes}

Electric hand drills are used to drill the holes for the installation of the injection pipes. This drilling system does not transmit vibrations to the structure. These perforations are $26 \mathrm{~mm}$ in diameter and were made with screw augers of different lengths to reach the exact depth of the soil to be treated, in this case 2.00, 2.40 and 3.00 meters. The perforations were spaced 1.50 meters apart.

The injection pipes were installed by vibration using electrical equipment. The pipes were made of steel with outer diameters of $12 \mathrm{~mm}$ and equipped with concealed valves to prevent the obstruction of the pipe as it is being installed in the soil. The length of the injection pipes was determined based on the theoretical injection depth and the inclination of the pipe relative to the vertical axis starting from the work platform. Allowed tolerance for deviations \pm $10 \mathrm{~cm}$.

\section{The resin injection process}

Once the pipes are installed, the injection of the Geoplus resin begins. The resin is injected using and "injection gun" that is fitted to the upper end of the installed injection pipe. The two components of the resin are transported separately to the "injection gun" and mixed under high pressure in a chamber located at the rear. This ensures a perfect mixture of the two components before the mixture is added to the injection pipe and then into the soil.

This process continues at each injection point until the lifting of the structure is first observed. Lifting is the element that makes it possible to check the injection efficiency in real time. 
A laser level with an accuracy up to $0.1 \mathrm{~mm}$ was used to control the lifting of the structure, which also made it possible to detect vertical microshifting during the injection. Real time monitoring of the structure is also possible with this instrumentation.

The laser level was positioned at a certain distance from the injection point to prevent it from being affected by the injection process. The set-up consists of the level and various targets attached to the structure to be treated. These targets detect variations in the lift respect to the fixed horizontal reference plane set by laser the laser (Figure 9).

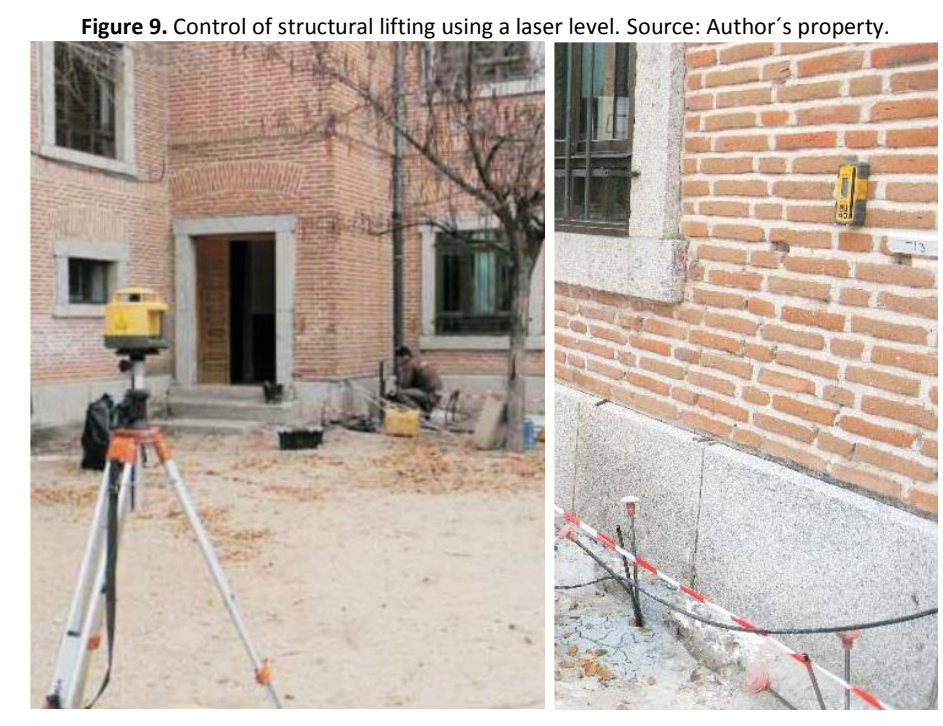

The interruption or cessation of the injection process is determined based on this monitoring, which allows you to control the lifting and to avoid unwanted shifting of the structure being treated. The best evidence of the effectiveness of the injection are the liftings recorded in the control systems.

Following the injection, a geotechnical study was conducted using DPM (Dynamic Probing Medium) (AENOR-CEN, 1993) in order to verify the improvements achieved in terms of the load-bearing capacity of the soil. These dynamic penetration tests were carried out at the same site and with the same equipment that was used to characterise the soil prior to injection. The test results performed after and before the soil consolidation treatment have been compared. This assessment allows evaluating the improvement of the soil profile. It has been verified that the consolidation state of the soil profile has improved an average value of $41 \%$.

This comparative study shows the improvement to the soil in terms of penetration resistance, which is indicative of the load-bearing capacity of the treated soil (Figure 10). 


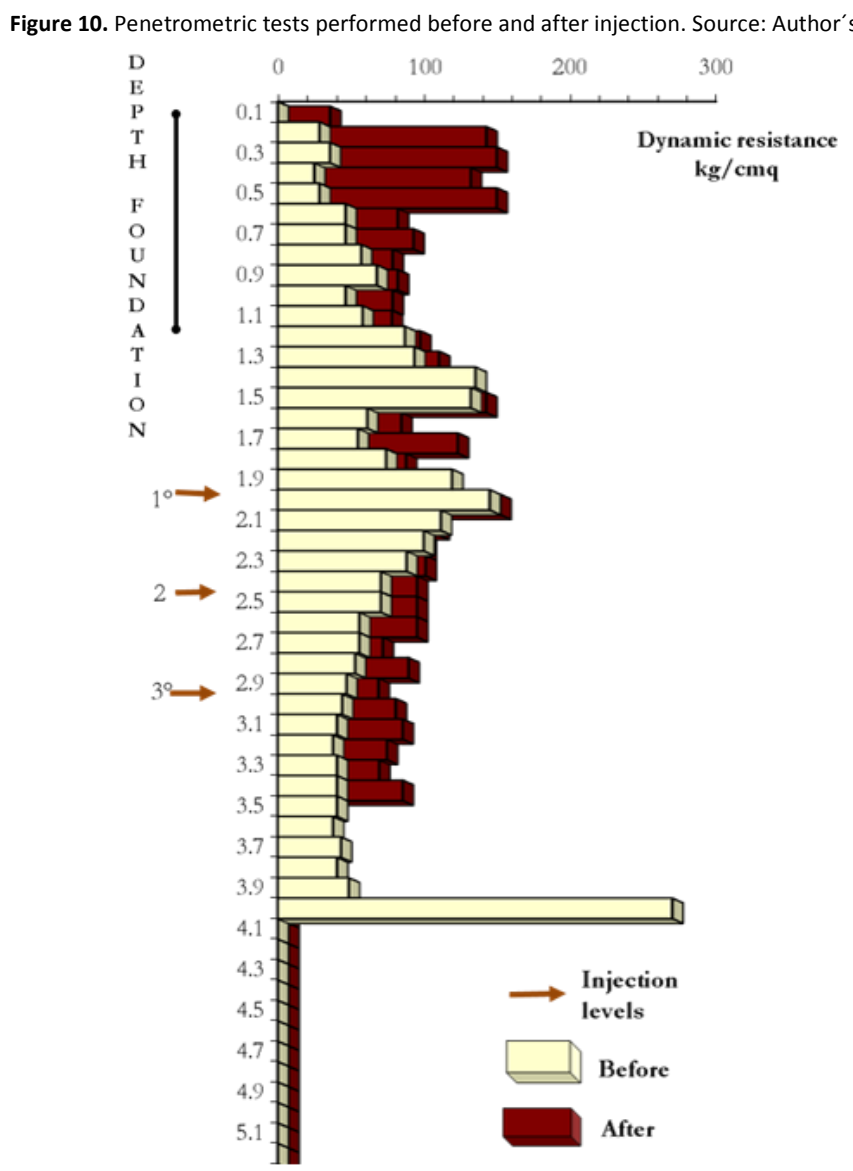

\section{Discussion and Conclusions}

The injection of expanding polyurethane resin into the soil is a technology that is being used more frequently in interventions for underpinning shallow foundations in order to improve the mechanical properties of the soil and correct differential settlement.

It is noteworthy that this technology has been used on buildings of great historical value which are part of the country's architectural heritage.

The principle of the technology used for underpinning shallow foundations is based on the injection of a certain volume of expanding polyurethane resin (Geoplus) into the soil, which then expands, enveloping the soil around the injection site (Yu \& Carter, 2002) (Yu \& Houlsby, 1992).

The expansion is accompanied by a reduction in swelling pressure and an increase in the average confining stress. The process stops when it reaches the equilibrium pressure.

The resin penetrates into the terrain to be treated, increasing in volume and compressing the soil in all directions radial expansion - favouring the pathways that offer the least resistance (Buzzi, Fityus, Sasaki \& Sloan, 2008). The resin continues to expand until the soil prevents any further radial compression. At that At that point, the only possibility for expansion is an upward displacement of the soil.

This process continues at each injection point until the lifting of the structure is first observed. When the initial lifting is observed, it means that the consolidating action is being directed vertically upward and that this is the direction that offers the least resistance, while the surrounding soil offers greater resistance in respect of the decrease in the structural load. This shows that the foundation soil has been compacted enough to withstand not only the increase of static loads, but also the loads developed as a result of the lifting (Salgado, Mitchell, \& Jamiolkowski, 1997). 
Apuani, T., Giani, G. P., d'Attoli, M., Fischanger, F., Morelli, G., Ranieri, G., ... Santarato, G. (2015). Assessment of the Efficiency of Consolidation Treatment through Injections of Expanding Resins by Geotechnical Tests and 3D Electrical Resistivity Tomography. TheScientificWorldJournal, 2015, 237930. https://doi.org/10.1155/2015/237930

Bilotta, E. (2013). Geotechnical engineering for the preservation of monuments and historic sites. CRC Press/Balkema.

Buzzi, O., Fityus, S., Sasaki, Y., \& Sloan, S. (2008). Structure and properties of expanding polyurethane foam in the context of foundation remediation in expansive soil. Mechanics of Materials, 40(12), 1012-1021. https://doi.org/10.1016/J.MECHMAT.2008.07.002

Buzzi, O., Fityus, S., \& Sloan, S. W. (2010). Use of expanding polyurethane resin to remediate expansive soil foundations. Canadian Geotechnical Journal, 47(6), 623-634. https://doi.org/10.1139/T09-132

Dei Svaldi, A., Favaretti, M., Pasquetto, A., \& Vinco, G. (2005). Analytical modelling of the soil improvement by injections of high expansion pressure resin. Bulletin Fuer Angewandte Geologie.

Escolano-Sánchez, F., Bueno-Aguado, M., \& Fernández-Ordóñez, D. (2015). Análisis comparativo entre el método por elementos finitos (FEM) y el método clásico $(\mathrm{MC})$ en la estimación de asientos y cálculo del coeficiente de balasto para el diseño de losas de cimentación en zonas afectadas por cavidades naturales o antrópicas. Informes de La Construcción, 67(537), 69.

Escolano Sánchez, F., Bueno Aguado, M., \& Lavín, J. R. S. (2014). Interpretation of the pressuremeter test using numerical models based on deformation tensor equations. Bulletin of Engineering Geology and the Environment, 73(1), 141-146. https://doi.org/10.1007/s10064-0130528-x

Henderson, T. O., Taylor, R. N., Harris, D. I., Mair, R. J., \& Love, J. P. (1994). Observations of ground and structure movements for compensation grouting during tunnel construction at Waterloo station. Géotechnique, 44(4), 691-713. https://doi.org/10.1680/geot.1994.44.4.691

Manassero, M. (2013). Coupled Phenomena in Environmental Geotechnics. CRC Press (an imprint of Taylor \& Francis).

Manassero, M., Dominijanni, A., Foti, S., \& Musso, G. (2016). Design, construction \&amp; controls of soil improvement systems. Proceedings of the XXIV Edition of the Geotechnical Conference of Torino (XXIV Ciclo delle Conferenze di Geotecnica di Torino - XXIV CGT). Retrieved from http://porto.polito.it/2642507/

Salgado, R., Mitchell, J. K., \& Jamiolkowski, M. (1997). Cavity Expansion and Penetration Resistance in Sand. Journal of Geotechnical and Geoenvironmental Engineering, 123(4), 344-354. https://doi.org/10.1061/(ASCE)1090-0241(1997)123:4(344)

Uretek. (2014). URETEK web page. Retrieved from http://www.uretek.es/

VINSON, T. S., \& Mitchell, J. K. (1972). POLYURETHANE FOAMED PLASTICS IN SOIL GROUTING. Journal of Soil Mechanics \& Foundations Div, 98(sm6). Retrieved from https://trid.trb.org/view.aspx?id=125517

Yu, H. S., \& Carter, J. P. (2002). Rigorous Similarity Solutions for Cavity Expansion in Cohesive-Frictional Soils. International Journal of Geomechanics, 2(2), 233-258. https://doi.org/10.1061/(ASCE)1532-3641(2002)2:2(233)

Yu, H. S., \& Houlsby, G. T. (1992). Discussion: Finite cavity expansion in dilatant soils: loading analysis. Géotechnique, 42(4), 649-654. https://doi.org/10.1680/geot.1992.42.4.649 